\title{
Penguraian Zat Warna Tartrazin Pada Limbah Pencucian Mie Aceh Secara Ozonolisis Dan Penyinaran Matahari Dengan Penambahan Katalis ZnO
}

\author{
Bhayu Gita Bhernama \\ Program Studi Kimia, Fakultas Sains dan Teknologi \\ Universitas Islam Negeri Ar-Raniry \\ email: deta.chavez1678@gmail.com
}

\begin{abstract}
People's habits in consuming Aceh noodles make the noodle industry grow rapidly, but the waste treatment process becomes less effective. In the process of making the noodles, dye waste is produced in the form of tartrazine dye and need to be processed before being disposed into the environment. The research purpose was to describe the decomposition of tartrazine using ozonolysis and solar radiation methods as one of the solutions in the waste treatment process. The use of $\mathrm{ZnO}$ as catalyst is to accelerate the decomposition reaction of the noodle washing wastes. The results of the analysis concluded that ozonolysis methods are more effective in decomposing tartrazine in the noodle wash wasted by solar irradiation method. The sun exposure decomposed tartrazine by $99.74 \%$ using $0.015 \mathrm{~g} \mathrm{ZnO}$ for $150 \mathrm{~min}$ and tartrazine content obtained $0.022 \mathrm{mg} / \mathrm{L}$ with a sunlight intensity of $1.24 \times 1016 \mathrm{~cm}^{-2} \mathrm{~s}^{-1}$. Ozonolisis exposure decomposed tartrazine by $98.68 \%$ using $0.020 \mathrm{~g} \mathrm{ZnO}$ for 12 minutes and tartrazine content obtained $0.112 \mathrm{mg} / \mathrm{L}$.
\end{abstract}

Keywords : aceh noodle, ozonolysis, solar radiation, tartrazin, $\mathrm{ZnO}$

\section{PENDAHULUAN}

Seiring perkembangan zaman, kemajuan diberbagai bidang juga ikut berkembang, baik industri, transportasi, komunikasi dan teknologi. Perkembangan dibidang industri semakin pesat dan keberadaannya membawa dampak positif dan negatif bagi lingkungan dan masyarakat. Dampak positif adanya industri antara lain pendapatan kapita daerah meningkat dan adanya lapangan kerja. Dampak negatif adanya industri berupa timbulnya pencemaran lingkungan. Pencemaran lingkungan yang disebabkan oleh industri adalah pencemaran yang disebabkan oleh limbah cair yang mengalir ke perairan tanpa adanya pengolahan terlebih dahulu sehingga membahayakan kehidupan ekosistem didalamnya (Setyaningtyas \& Dwiasi, 2012)

Industri yang berkontribusi besar menghasilkan limbah adalah industri makanan yang menggunakan bahan aditif makanan berupa zat warna. Industri makanan yang biasa menggunakan zat warna makanan seperti industri mie. Industri mie pada saat ini mulai berkembang, akan tetapi tidak diiringi dengan pengolahan limbah yang baik. Limbah dari industri ini pada umumnya menggunakan zat warna sintetis berupa tartrazin. Tartrazin merupakan zat warna sintetis kuning yang membahayakan kesehatan dan dapat menimbulkan penyakit kanker, asma dan alergi karena sifatnya yang karsinogen. Oleh karena itu, zat warna tartrazin perlu diolah sebelum dibuang ke lingkungan.

Pengolahan limbah zat warna sintetis sebelum dibuang ke lingkungan telah banyak dilakukan seperti koagulasi, oksidasi dan elektrokimia. Namun metoda ini kurang efektif dalam 
penanggulangannya karena menghasilkan polutan yang lebih terkonsentrasi. Beberapa metoda telah banyak dikembangkan seperti biodegradasi, kloronisasi dan ozonisasi. Penelitian tentang zat warna tartrazin pada limbah industri mie telah banyak dilakukan seperti Setyaningtyas \& Dwiasi (2012) telah melakukan degradasi zat warna tartrazin pada limbah industri mie dengan metoda AOPs (Advance Oxidation Proceses), dimana metoda ini menghasilkan persen degradasi yang besar selama 2,5 jam pada $\mathrm{pH}=2$. Akan tetapi, penggunaan metoda ozonolisis dan penyinaran matahari terhadap zat warna tartrazin pada limbah pencucian mie aceh oleh pedagang mie di aceh besar dengan katalis $\mathrm{ZnO}$ tidak banyak dilakukan. Hal ini juga melatarbelakangi peneliti untuk melakukan penelitian ini. Penelitian ini dilakukan berdasarkan variasi waktu dan berat katalis.

\section{METODE PENELITIAN}

Alat

Alat yang digunakan dalam penelitian ini antara lain, magnetik stirer, penangas air, alat gelas, sentrifunge, spektrofotometer UV-Vis (Shimandzu), kertas saring Whattman dan stopwatch.

\section{Bahan}

Bahan yang digunakan pada penelitian ini yaitu sampel limbah pencucian mie aceh, akuabides, dan $\mathrm{ZnO}$.

\section{Prosedur Kerja}

Preparasi sampel

Limbah pencucian mie aceh yang mengandung tartrazin diperoleh dari pedagang mie aceh yang berada di Aceh Besar. Mie aceh yang telah dibeli dari pedagang mie dicuci dan dibersihkan. Air cucian mie aceh tersebut kemudian dianalisis dan diteliti.

\section{Pembuatan Kurva Kalibrasi}

Sebanyak 0,1 gram zat warna tartrazin dilarutkan dalam $100 \mathrm{ml}$ akuabides, diencerkan pada 5 variasi kosentrasi 1, 3, 5, 7, 9 dan $11 \mathrm{mg} / \mathrm{L}$. Kemudian larutan zat warna tartrazin diukur absorban pada panjang gelombang $(\lambda) 427 \mathrm{~nm}$. Dibuat kurva standar kalibrasi. Sampel awal sebelum perlakuan diukur nilai absorbannya, kemudian diplotkan kedalam kurva kalibrasi sehingga diperoleh kosentrasi awal sampel.

\section{Pengaruh variasi waktu kontak}

Sebanyak $250 \mathrm{ml}$ masing-masing sampel limbah pencucian mie aceh ditambahkan ke dalam 10 buah gelas piala. Kemudian, 5 buah gelas piala yang telah berisikan sampel limbah pencuaian mie aceh ditempatkan dibawah sinar matahari dengan variasi waktu 30, 60, 90, 120 dan 150 menit. 5 buah gelas piala yang lainnya, di ozonolisis selama 1,3,6,9 dan 12 menit. Kemudian diukur nilai absorbansi pada panjang gelombang $(\lambda) 427 \mathrm{~nm}$. Absorbansi yang terukur diplotkan pada kurva kalibrasi untuk mengetahui konsentrasi tartrazin pada limbah pencucian mie aceh. Selisih antara konsentrasi awal sebelum perlakuan dan setelah perlakuan merupakan banyaknya tartrazin yang terurai. 


\section{Pengaruh penambahan katalis $\mathrm{ZnO}$ pada waktu optimum penguraian}

Sebanyak $250 \mathrm{ml}$ masing-masing sampel limbah pencucian mie aceh ditambahkan ke dalam 10 buah gelas kemudian ditambahkan ZnO sebanyak 0,005;0,010;0,015;0,020 dan 0,025 g. Kemudian 5 buah gelas piala, ditempatkan dibawah sinar matahari dengan waktu kontak optimum dan diaduk dengan magnetik stirrer. Sisa sampel hasil penyinaran di endapkan selama 12 jam, selanjutnya disentrifunge selama 30 menit. 5 buah gelas piala lainnya dilakukan ozonolisis dengan waktu kontak optimum dan diaduk dengan magnetik stitter. Sisa sampel hasil penyinaran di endapkan selama 12 jam, selanjutnya disentrifunge selama 30 menit. Kemudian diukur nilai absorbansi pada panjang gelombang $(\lambda) 427 \mathrm{~nm}$. Absorbansi yang terukur diplotkan pada kurva kalibrasi untuk mengetahui konsentrasi tartrazin pada limbah pencucian mie aceh

\section{Penentuan Intensitas Sinar Matahari}

Penentuan intensitas sinar matahari dilakukan dengan menggunakan metoda aktinometri uranil oksalat. Sebanyak $50 \mathrm{ml}$ larutan uranil asetat 0,02 M (larutan A) ditambahkan $50 \mathrm{ml}$ larutan asam oksalat 0,06 M (larutan B) perbandingan larutan A dan larutan B, $1: 1$ ). Sebanyak $5 \mathrm{ml}$ larutan campuran diatas dimasukan ke dalam erlenmeyer dan ditambahakan 3 tetes asam sulfat pekat lalu dipanaskan. Dalam keadaan panas dititrasi dengan larutan kalium permanganat 0,02 M sampai warna kalium permanganat tepat tidak hilang oleh pengocokan selanjutnya, lalu catat volume kalium permanganat yang terpakai (sebagai blanko). Selanjutnya $25 \mathrm{ml}$ larutan campuran (a) diambil lagi dan dituangkan ke dalam petridish, dibiarkan di bawah sinar matahari selama 5 menit. Sebanyak $5 \mathrm{ml}$ larutan hasil penyinaran dimasukan ke dalam erlenmeyer, ditambahakan 3 tetes asam sulfat pekat dan dipanaskan. Dalam keadaan panas titrasi dengan kalium pemanganat sampai warna tepat tidak hilang oleh pengocokan selanjutnya, volume kalium permanganat yang terpakai dicatat. Berdasarkan selisih konsentrasi oksalat antara blanko ( yang tidak disinari dengan larutan yang telah disinari maka besarnya intensitas sinar matahari dapat ditentukan. (Bhernama \& Safni, 2014) dengan persamaan berikut:

$$
\mathrm{I}=\frac{(\mathrm{Co}-\mathrm{C}) \mathrm{mol} / \mathrm{L} \times 10-3 \mathrm{~L} / \mathrm{ml} \times 6,02 \times 1023 \mathrm{molekul} / \mathrm{mol} \times 5 \mathrm{ml}}{\emptyset \mathrm{molekul} / \mathrm{foton} \times 600 \mathrm{sekon} \times 66,4424 \mathrm{~cm} 2}
$$

Keterangan :

$$
\begin{aligned}
& \mathrm{T}=600 \text { detik } \quad \mathrm{N}=6,02 \times 10^{23}{\text { molekul } \mathrm{mol}^{-1}}^{-1} \\
& \mathrm{Co}=\text { kosentrasi awal } \quad \varnothing=0,56 \text { molekul foton }^{-1} \\
& \mathrm{C}=\text { konsentasi akhir } \quad \mathrm{A}=66,4424 \mathrm{~cm}^{2}
\end{aligned}
$$

\section{HASIL DAN PEMBAHASAN \\ Preparasi sampel}

Sampel limbah Mie Aceh diambil dengan teknik random ke pedagang mie di beberapa daerah di Banda Aceh, yaitu di daerah Darussalam, Kuta Alam, Lambaro Skep dan daerah pasar 


\section{Bhernama, B.G}

aceh. Mie yang telah dibeli di pedagang dicuci dan dimasukan ke dalam wadah derigen 5 L, kemudian diberi label, seperti pada Tabel 1. Setelah pengambilan sampel limbah mie dilakukan, sampel dianalisis.

Tabel 1. Daerah pengambilan sampel

\begin{tabular}{cc}
\hline Kode & Nama Daerah \\
\hline A & Darussalam \\
B & Kuta Alam \\
C & Lambaro Skep \\
D & Pasar Aceh \\
\hline
\end{tabular}

\section{Kurva Kalibrasi}

Sampel awal limbah pencucian mie aceh diukur nilai absorbansinya pada panjang gelombang, $\lambda 427 \mathrm{~nm}$, dan dari hasil pengukuran diperoleh nilai absorbansi sampel awal sebelum perlakuan sebesar 0,764. Konsentrasi awal sampel sebelum perlakuan dihitung dengan memplotkan atau memasukan nilai absorbansi ke dalam persamaan regresi dari kurva kalibrasi sehingga diperoleh konsentrasi sampel 8,517 mg/L. Hubungan antara absorbansi dengan variasi konsentrasi larutan standar tartrazin dapat dilihat pada gambar 1. Dari gambar 1 diperoleh persamaan regresi $y=0,089 x+0,006$ dan $R^{2}=0,999$.

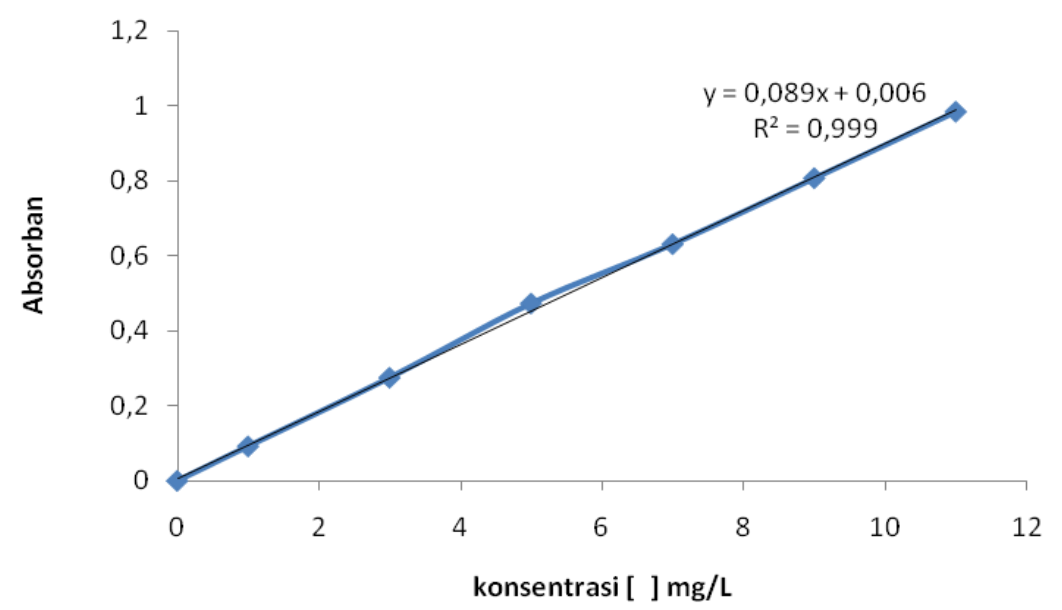

Gambar 1. Kurva kalibrasi Larutan tartrazin

\section{Pengaruh variasi waktu penguraian}

Pengaruh waktu degradasi terhadap persen penguraian tartrazin pada sampel limbah pencucian mie aceh secara ozonolisi dapat dilihat pada Gambar 2. 


\section{Bhernama, B.G}

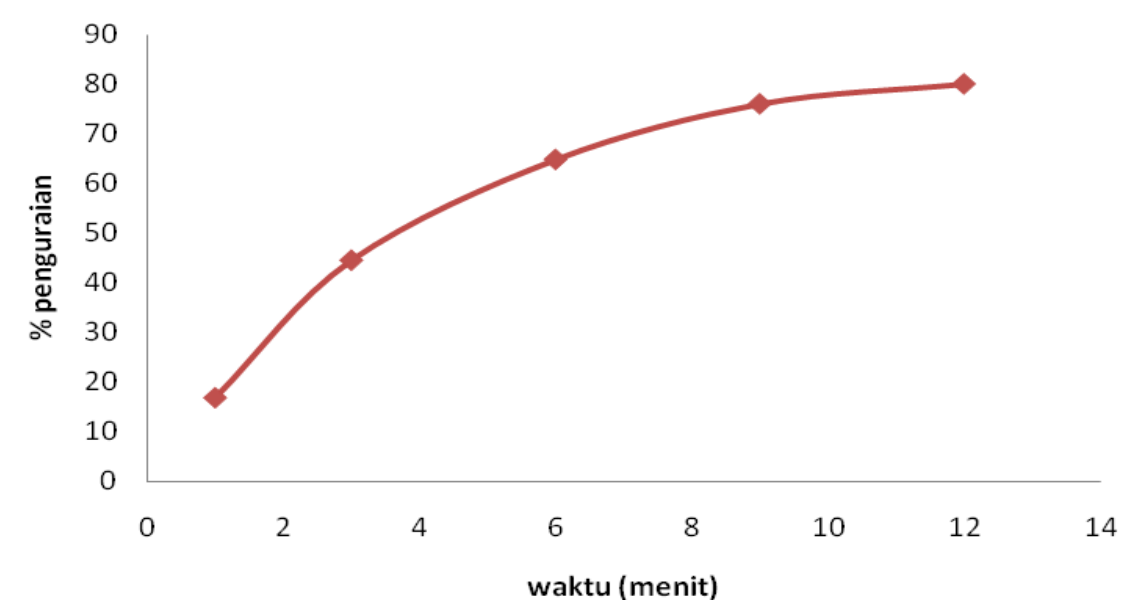

Gambar 2. Pengaruh variasi waktu terhadap persen penguraian sampel limbah pencucian mie Aceh secara ozonolisis

Dari Gambar 2 dapat dilihat bahwa sampel limbah pencucian mie Aceh dengan konsentrasi awal sebelum perlakuan yaitu $8,517 \mathrm{mg} / \mathrm{L}$ dilakukan penguraian dengan mengalirkan gas ozon tanpa penambahan katalis dengan variasi waktu, menghasilkan persen penguraian yang semakin besar seiring dengan bertambahnya waktu. Waktu optimum didapatkan setelah dialiri gas ozon ke dalam sampel selama 12 menit tanpa penambahan katalis menghasilkan persen penguraian $80 \%$ dengan konsentrasi 1,022 mg/L. Data nilai absorbansi, konsentrasi dan persen penguraian sampel limbah dapat dilihat pada tabel 2.

Tabel 2. Nilai absorbansi, konsentrasi dan persen penguraian sampel limbah pencucian mie Aceh secara ozonolisis berdasarkan variasi waktu

\begin{tabular}{cccc}
\hline $\begin{array}{c}\mathbf{t} \\
\text { (menit) }\end{array}$ & $\mathbf{A}$ & $\begin{array}{c}\text { Konsentrasi } \\
\mathbf{m g} / \mathbf{L}\end{array}$ & $\begin{array}{c}\text { \% } \\
\text { degradasi }\end{array}$ \\
\hline $\mathbf{1}$ & 0,637 & 7,089 & 16,77 \\
$\mathbf{3}$ & 0,418 & 4,629 & 44,48 \\
$\mathbf{6}$ & 0,273 & 3 & 64,78 \\
$\mathbf{9}$ & 0,156 & 1,685 & 75,99 \\
$\mathbf{1 2}$ & 0,097 & 1,022 & 80 \\
\hline
\end{tabular}

Tabel 2 memperlihatkan nilai absorbansi, konsentrasi dan persen penguraian berdasarkan variasi waktu ozonolisis. Semakin lama gas ozon dialirkan pada tartrazin semakin banyak radikal $\mathrm{OH}$ yang dihasilkan, sehingga persen degradasi yang didapatkan semakin besar. Radikal $\mathrm{OH}$ yang dihasilkan dari proses ozonolisis tidak hanya menyerang senyawa pada permukaan larutan saja, akan tetapi dapat menyerang senyawa yang berada dalam larutan (Fendri, Safni \& Suryani, 2017). 


\section{Bhernama, B.G}

Limbah pencucian mie aceh diuraikan dengan menempatkan 5 buah sampel dalam gelas piala dibawah sinar matahari selama 30, 60, 90, 120 dan 150 menit. Waktu optimum penguraian limbah pencucian mie aceh yang didapatkan yaitu 150 menit dengan besar penguraian 99,21\% dan konsentrasi menjadi $0,067 \mathrm{mg} / \mathrm{L}$, dapat dilihat pada tabel 3. Pengaruh waktu dan besar penguraian dengan penyinaran matahari dapat dilihat pada Gambar 3.

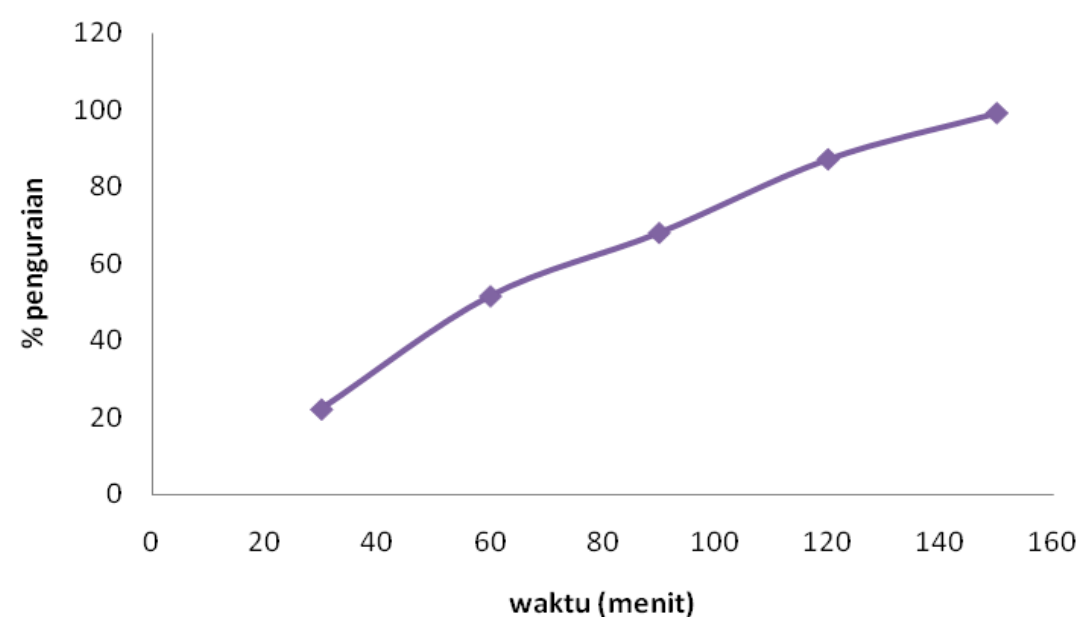

Gambar 3. Pengaruh waktu kontak terhadap persen penguraian sampel limbah pencucian mie Aceh dengan penyinaran matahari

Persentase penurunan kadar tartrazin pada limbah pencucian mie aceh selama 150 menit menunjukan bahwa proses penyerapan energi foton $(h v)$ paling efektif. Menurut Dian $d k k$ (2014) penyerapan foton $(h v)$ menyebabkan banyaknya elektron pada pita valensi mengalami eksitasi ke pita kondukasi. Peristiwa eksitasi tersebut banyak membentuk lubang positif (hole ${ }^{+}$), kemudian hole ${ }^{+}$akan bereaksi dengan $\mathrm{H}_{2} \mathrm{O}$ dan ion hidroksi membentuk radikal hidroksil $(\bullet \mathrm{OH})$ yang pada proses selanjutnya digunakan untuk menguraikan senyawa organik termasuk senyawa tartrazin pada limbah pencucian mie Aceh.

Tabel 3. Nilai absorbansi, konsentrasi dan persen penguraian sampel limbah pencucian mie Aceh dengan penyinaran matahari berdasarkan variasi waktu

\begin{tabular}{llll}
\hline $\mathbf{t}$ & $\mathrm{A}$ & Konsent & $\%$ \\
\hline
\end{tabular}




\begin{tabular}{crrr}
\hline (menit) & \multicolumn{2}{c}{ rasi mg/L } & \multicolumn{1}{c}{ degradasi } \\
\hline $\mathbf{3 0}$ & 0 & 6,629 & 22,17 \\
&, 596 & & \\
$\mathbf{6 0}$ & 0 & 4,123 & 51,59 \\
&, 373 & & \\
$\mathbf{9 0}$ & 0 & 2,719 & 68,06 \\
&, 248 & & \\
$\mathbf{1 2 0}$ & 0 & 1,089 & 87,21 \\
&, 103 & & \\
$\mathbf{1 5 0}$ & 0 & 0,067 & 99,21 \\
&, 012 & & \\
\hline
\end{tabular}

Pengaruh penambahan katalis $\mathrm{ZnO}$ pada waktu optimum penguraian

Penguraian senyawa tartrazin pada limbah pencucian mie aceh dengan penambaha berat katalis $\mathrm{ZnO} 0,005 ; 0,010 ; 0,015 ; 0,020$; dan 0,025 g. Penurunan kadar tartrazin menggunakan gas ozon terjadi kondisi berat optimum $\mathrm{ZnO} 0,020 \mathrm{~g}$ dengan persen penguraian 98,68\% dan dengan penyinaran matahari terjadi penurunan kadar tartrazin pada kondisi berat optimum 0,015 gram s ebesar 99,78\%, dapat dilihat pada Tabel 4 dan 5.

Tabel 4. Nilai absorbansi, konsentrasi dan persen penguraian sampel limbah pencucian mie Aceh secara ozonolisis berdasarkan variasi penambahan berat katalis $\mathrm{ZnO}$

\begin{tabular}{ccrcr}
\hline $\begin{array}{c}\text { Berat katalis } \\
\text { (gram) }\end{array}$ & A & $\begin{array}{c}{[]} \\
\text { mg/L }\end{array}$ & $\begin{array}{c}\text { \% } \\
\text { degradasi }\end{array}$ \\
\hline & $\mathbf{0 , 0 0 5}$ & 0 & 6,326 & 25,73 \\
&, 569 & & \\
& $\mathbf{0 , 0 1 0}$ & 0 & 3,356 & 60,59 \\
&, 302 & & \\
& $\mathbf{0 , 0 1 5}$ & 0 & 1,213 & 85,76 \\
&, 114 & & \\
& $\mathbf{0 , 0 2 0}$ & 0 & 0,112 & 98,68 \\
&, 016 & & 64,12 \\
& $\mathbf{0 , 0 2 5}$ & 0 & & \\
&, 278 & 3,056 & \\
\hline
\end{tabular}

Tabel 5. Nilai absorbansi, konsentrasi dan persen penguraian sampel limbah pencucian mie aceh dengan penyinaran matahari berdasarkan variasi penambahan berat katalis $\mathrm{ZnO}$

\begin{tabular}{|c|c|c|c|}
\hline $\begin{array}{l}\text { Berat katalis } \\
\text { (gram) }\end{array}$ & A & $\begin{array}{c}{[]} \\
\mathrm{mg} / \mathrm{L}\end{array}$ & $\begin{array}{c}\% \\
\text { degradasi }\end{array}$ \\
\hline 0,005 & 0 & 4,843 & 43,14 \\
\hline & 437 & & \\
\hline
\end{tabular}




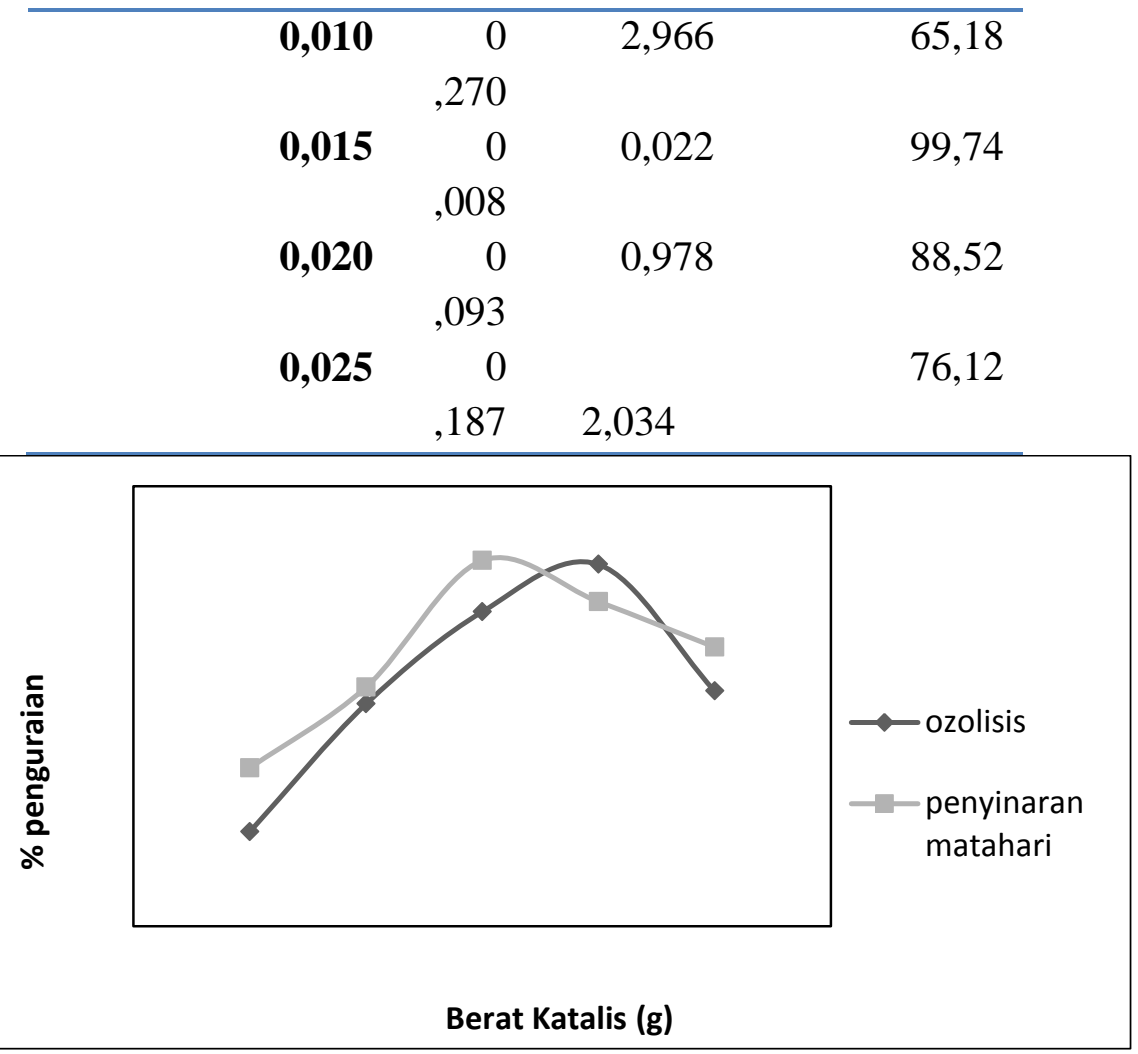

Gambar 4. Pengaruh variasi berat katalis terhadap persen penguraian sampel limbah pencucian mie aceh secara ozonolisis dan penyinaran matahari pada waktu optimum.

Pada Gambar 4 terlihat bahwa semakin bertambah berat katalis semakin besar penguraian senyawa tartrazin pada limbah pencucian mie aceh hingga tercapai kondisi berat optimum. Akan tetapi, setelah berat optimum tercapai, terjadi penurunan persen penguraian, hal ini disebabkan karena pada saat katalis dalam sampel disinari mengalami kejenuhan atau aglomerasi (penggumpalan) sehingga apabila katalis $\mathrm{ZnO}$ dipakai dalam keadaan berlebih berdampak pada kenaikan pembacaan serapan yang lebih besar (Zilfa, et.al, 2013).

\section{Penentuan Intensitas Sinar Matahari}

Nilai intensitas matahari (I) yang ditentukan melalui metoda aktinometri uranil oksalat didapatkan $1,24 \times 10^{16}$ foton $\mathrm{cm}^{-2} \mathrm{~s}^{-1}$.

\section{PENUTUP}

\section{Kesimpulan}

Penguraian limbah pencucian mie aceh dengan penambahan katalis $\mathrm{ZnO}$ secara ozonlisis lebih efektif dibandingkan dengan penyinaran matahari. Dari hasil analisis didapatkan penguraian dengan metoda ozonolisis menghasilkan persen penguraian sebesar 98,68\% dengan 


\section{Bhernama, B.G}

Penguraian Zat Warna Tartrazin Pada Limbah Pencucian Mie Aceh Secara

Ozonolisis Dan Penyinaran Matahari Dengan Penambahan Katalis ZnO

kadar tartrazin 0,112 mg/L selama 12 menit, sedangkan penyinaran matahari menghasilkan persen penguraian 99,74\% dengan kadar 0,022 mg/L selama 150 menit.

\section{DAFTAR PUSTAKA}

Bhernama, B.G. \& Safni, S. (2014), Degradasi of malacite green oxalate secara fotolisis dan

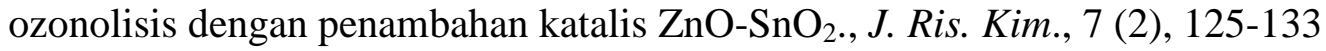

Dwiasi, D.W. \& Setyaningtyas, T. (2014), Fotodegradasi tartrazin pada limbah cair industri Mie menggunakan $\mathrm{TiO}_{2}$ fotokatalisis-penyinaran matahari., J. Ris. Kim 9 (1), 56 - 62.

Fendri, S.T.J., Safni, \& Suryani, H. (2017), Penggunaan $\mathrm{SnO}_{2}$ dan $\mathrm{TiO}_{2}$-anatase sebagai katalis degradasi carbaryl secara ozonolisis serta pendeteksiannya menggunakan spektrofotometer UV-Vis dan HPLC., Jurnal Katalisator., 2 (1), 39-52.

Setyaningtyas, T. \& Dwiasi., D.W., (2012), Degradation of ozo dye tartrazin in industrial wastewater of noodles with AOPs (advanced oxidation processes) method, Molekul, 7(2), 153-162

Rahayu, W.S, Tjiptasurasa, Najilah, P. (2009), Analisis zat warna tartrazin pada minuman orso dengan metoda spektrofotometri UV-Vis di Pasar Induk Brebes., Pharmacy, 6 (1), 94-102.

Zilfa, Yusuf, Y., Safni, Rahmi, W. (2013), Pemanfaatan $\mathrm{TiO}_{2}$ /zeolit alam sebagai pendegradasi pestisida (permetrin) secara ozonolisis., Prosiding Semirata FMIPA Universitas Lampung. 